\title{
Haemodynamic Response After induction of Anaesthesia in Patients undergoing Coronary Artery Bypass Grafting Surgery of Poor Left ventricular Function. A comparison between Thiopental / fentanyl and Etomidate / fentanyl
}

\author{
RAHMAN MH ${ }^{\mathrm{a}}$, MONDAL BC ${ }^{\mathrm{b}}$, AHMED N $^{\mathrm{c}}$, ISLAM ${ }^{\mathrm{d}}$, FARUQUEE ZA ${ }^{\mathrm{e}}$
}

\begin{abstract}
:
Objective: To compare the haemodynamic effect of thiopental/fentanyl with etomidate/fentanyl during anaesthetic induction in patients with coronary artery disease with poor left ventricular function (ejection fraction <45\%). Design: A retrospective randomized trial. Setting: Ibrahim Cardiac Hospital and Research Institute. Participants: Twenty patients with coronary artery disease of poor left ventricular function (ejection fraction<45\%) scheduled for elective coronary artery bypass surgery. Interventions: Patients were allocated randomly to receive either thiopental/fentanyl or etomidate/fentanyl for induction. Measurement \& Main Results: Haemodynamic response (heart rate, mean arterial pressure) were recorded at 1 minute interval starting from induction till five minutes
\end{abstract}

Introduction:

The deleterious effects of anaesthetic agents on patients who are suffering from coronary artery disease with poor left ventricular function are well known. There is

a. Prof. Lt Col (Retd) Md. Hamidur Rahman, Senior Consultant and Head, Department of Cardiac Anaesthesia, Ibrahim Cardiac Hospital \& Research Institute, Sahabagh, Dhaka 1000.

b. Dr. Bhabesh Chandra Mondal

Consultant, Department of Cardiac Anaesthesia, Square Hospital. Dhaka.

c. Prof. Dr. Niaz Ahmed, Consultant, Department of Cardio thoracic Anaesthesia \& ICU, Apollo Hospital, Dhaka.

d. Dr. Md. Sirajul Islam, Consultant \& Associate Professor, Department of Cardiac Anaesthesia, Ibrahim Cardiac Hospital \& Research Institute.

e. Lt Col (Retd). Dr. Z.A. Faruquee, Associate Consultant \& Assistant Professor, Department of Cardiac Anaesthesia, Ibrahim Cardiac Hospital \& Research Institute.

Address of Correspondence: Dr. Md Sirajul Islam..Consultant \& Associate Professor, Department of Cardiac Anaesthesia, Ibrahim Cardiac Hospital \& Research Institute. Mobile No - 01911386975, E-mail: drsislam08@gmail.com,drmukul@dhaka.net

Received: 07 August, 2012

Accepted: 12 October 2012 after intubations. The reduction of mean arterial pressure was greater in patients who received thiopental/fentanyl induction (maximal decrease 32\%) in comparison to etomidate/fentanyl induction (maximal decrease12\%) $[P<0.05$ which is statistically significant]. The changes of heart rate were insignificant between the groups (reduction of heart rate $8 \%$ versus $7 \%$ ). Conclusion: Etomidate/ fentanyl induction reduces less blood pressure in comparison to thiopental/fentanyl induction in patients of poor left ventricular function but changes of heart rate were insignificant in between the groups.

Key Words: Induction. Thiopental, Etomidate, Fentanyl, CABG Surgery, Left ventricular dysfunction.

(Birdem Med J 2013; 3(1):23-26)

lack of literature regarding the comparison between thiopental/fentanyl and etomidate/fentanyl induction in left ventricular dysfunction patients. Anaesthetic induction techniques for cardiovascular surgery are based on considering haemodynamic stability, effect on myocardial oxygen supply and demand ${ }^{1,2}$. Patients with coronary artery disease (CAD) and poor left ventricular function represent a high risk group. Various authors have concerns regarding induction of anaesthesia with agents such as etomidate, thiopentone, propofol and ketamine ${ }^{3,4,5}$. Etomidate is advocated in patients with compromised cardiopulmonary function, because of its minimal cardio respiratory depressant effects and lack of histamine release. Various studies have shown the stable cardiovascular profile of etomidate while others have shown stable haemodynamic of midazolam, thiopentone and propofol in patients of good ventricular function $6,7,8,9$. But here we compare thiopentone/fentanyl with etomidate/fentanyl induction in poor left ventricular function patients. 


\section{Materials \& Methods:}

Written informed consent was taken from the patients. Twenty patients with coronary artery disease with ejection fraction $>45 \%$ in each group were randomly allocated. GroupA - thiopentone / fentanyl and in Group B - etomidate / fentanyl. Patients with arrhythmia, IABP, emergency surgery, valvular heart disease, congestive heart failure and patient on mechanical ventilation, were excluded from this study. Induction was done by thiopentone $5 \mathrm{mg} / \mathrm{kg}$ in Group - A and etomidate 0.2mg/ $\mathrm{kg}$ in Group - B. All preoperative cardiac medications were continued till the morning of the surgery. All the patients received oral midazolam $7.5 \mathrm{mg}$ at night before surgery and one hour before induction of anaesthesia. In the operation theatre initial monitoring included five lead electrocardiogram, noninvasive blood pressure monitoring, and pulse oximetry. Then under local anaesthesia a 20G arterial line was placed in right radial artery and a tri -channel central venous catheter was placed in right internal jugular vein.

Intravenous fentanyl $5 \mu \mathrm{gm} / \mathrm{kg}$ were administered over one minute to all patients. After one minute, the baseline heart rate, systolic blood pressure, diastolic blood pressure and mean blood pressure were recorded during the study period in all the patients. Subsequently

Group-A patient was induced in with thiopentone $5 \mathrm{mg} /$ $\mathrm{kg}$ and in Group B with etomidate $0.2 \mathrm{mg} / \mathrm{kg}$. The induction agent was administered in small doses over one minute. After loss of eyelash reflex and loss of response to vocal command, pancuronium $0.1 \mathrm{mg} / \mathrm{kg}$ was administered. Tracheal intubations were done three minutes after induction. Initially the patients were ventilated manually by mask with $100 \%$ oxygen then mechanical ventilation was administered after intubations and was maintained with 50\% oxygen air mixture. Haemodynamic data was recorded one minute intervals starting from induction till five minutes.

\section{Result:}

The demographic characteristics were similar in between the two groups with regard to ejection fraction, preoperative medication, prevalence of diabetes mellitus and hypertension. All patients have moderate left ventricular dysfunction with ejection fraction ranging between 25 to 45\% (Table-1). Baseline haemodynamic parameters were similar between Group A and Group B. There was significant decrease of mean arterial pressure
Table-I

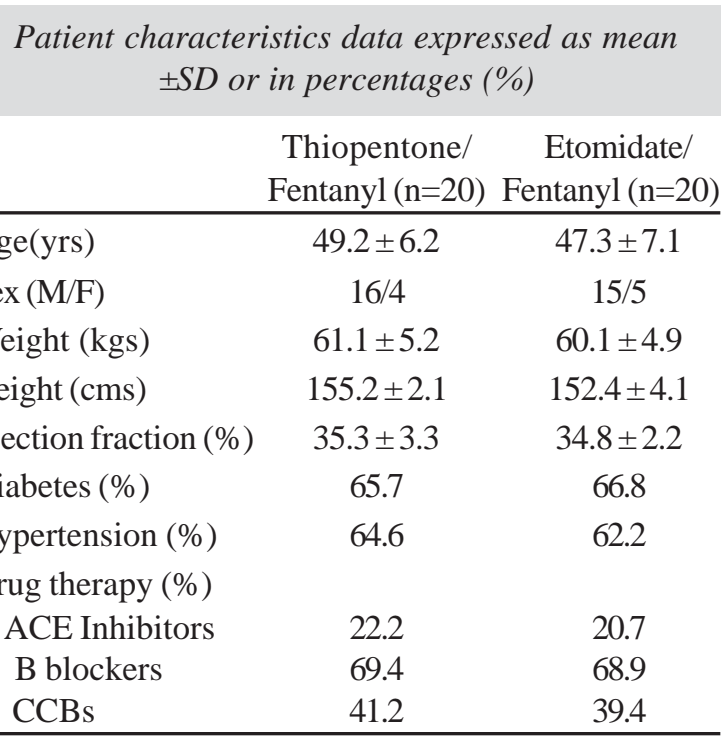

CCB-calcium channel blocker, ACE-Angiotensin converting enzyme

in Group A in comparison to Group B after induction $[\mathrm{P}<0.05]$ which is statistically significant (Table-2). There was maximum decrease of mean arterial pressure 32\% in Group A and 12\% in Group B after induction (Table-2) $[\mathrm{P}<0.05]$. The reduction of heart rate was $8 \%$ in Group A and $7 \%$ in Group B after induction [Table-2]. The changes of heart rate were insignificant in between the groups after induction.

\section{Table-II}

Hemodynamic variables between the two groups

\begin{tabular}{lcc} 
Heart rate (/min) & $\begin{array}{c}\text { Thiopentone/ } \\
\text { Fentanyl }\end{array}$ & $\begin{array}{c}\text { Etomidate/ } \\
\text { Fentanyl }\end{array}$ \\
\hline Baseline (HR-0) & $73.4 \pm 12.3$ & $74.1 \pm 11.1$ \\
1 min after induction (HR-1) & $68.2 \pm 11.6$ & $72.2 \pm 11.2$ \\
2 in after induction (HR-2) & $67.4 \pm 10.3$ & $72.5 \pm 10.3$ \\
3 min after induction (HR-3) & $66.6 \pm 10.1$ & $71.9 \pm 10.5$ \\
4 min after induction (HR-4) & $65.2 \pm 11.2$ & $71.3 \pm 10.9$ \\
5 min after induction (HR-5) & $64 \pm 10.4$ & $71.6 \pm 10.6$ \\
Mean arterial BP(mmHg) & & \\
Baseline (MAP-0) & $99.4 \pm 8.8$ & $100.1 \pm 8.9$ \\
1 min after induction (MAP-1) & $88.3 \pm 10.6$ & $96.2 \pm 10.3$ \\
2 min after induction (MAP-2) & $86.6 \pm 11.3$ & $96.0 \pm 9.9$ \\
3 min after induction (MAP-3) & $87.2 \pm 12.4$ & $95.4 \pm 10.9$ \\
4 min after induction (MAP-4) & $85.9 \pm 9.4$ & $96.8 \pm 11.2$ \\
5 min after induction (MAP-5) & $84.5 \pm 11.2$ & $97.5 \pm 8.8$ \\
\hline
\end{tabular}

Data are expressed as mean $\pm \mathrm{SD}$. Pair wise analysis was done by ANOVA test. 


\section{Discussion:}

During coronary artery bypass grafting, induction of general anaesthesia is a critical period in patients with poor left ventricular function. A wide variety of anaesthetic drugs eg. thiopentone, etomidate, midazolam and propofol are available for induction of general

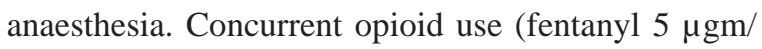
$\mathrm{kg}$ ) has been shown to produce minimal cardiovascular changes ${ }^{3}$. Decrease mean arterial pressure in patients of poor ventricular function after induction of anaesthesia is probably due to depression of sympathetic activity. As an induction agent etomidate has minimum cardiac depression and histamine release effect in comparison to thiopentone ${ }^{9}$.

The new emulsion preparation of etomidate has decreased the incidence of some adverse effects eg. thrombophlebitis and myoclonus. There is transient decrease of serum cortisol level after a single induction etomidate ${ }^{10}$. Laboratory studies indicate that etomidate is 25 times more potent and has a therapeutic index six times greater than sodium thiopental. Etomidate is an anaesthetic induction agent in patients with significant cardiovascular disease ${ }^{(11)}$. Jellish WS and collegues compared etomidate versus thiopental sodium as induction agent on 66 ASA physical status II and III inpatients undergoing neurosurgical procedures. In there study they found etomidate based induction can provide better hemodynamics than thiopental sodium based anaesthetic induction 12 .

Reiz et al. studied the effects of thiopentone on the cardiac performance of eight patients with stable CAD and normal ventricular function (7). Thiopentone in a dose of $6 \mathrm{mg} / \mathrm{kg}$ (given over two minutes) decreased arterial blood pressure (27\%), while the heart rate increased (10\%). With these hemodynamic changes they also demonstrated a decrease in myocardial oxygen consumption ( $\mathrm{MVO}_{2}$ fell 39\%), which was beneficial to the patients. Their patients were not premedicated and none of them received concurrent opioids, which could have accounted for the slightly greater decrease in heart rate from our thiopentone group. Concerns regarding the use of thiopentone in CAD patients originated from studies that had shown increase in heart rate and increase in myocardial oxygen uptake with thiopentone ${ }^{13}$. Reiz et al., however, postulated that this hemodynamic effect was probably related to a different administration technique i e thiopentone $4 \mathrm{mg} / \mathrm{kg}$ was administered over 30 seconds. In our study the reduction of mean arterial pressure was greater (maximal decrease 32\%) in Group A (thiopental / fentanyl induction) in comparison to Group B (etomidate / fentanyl induction) which is statistically significant $[\mathrm{P}<0.05]$. The changes of heart rate were insignificant in between the groups (reduction of heart rate $8 \%$ versus $7 \%$ ).

Lischke et al. evaluated the ST segment changes after induction with etomidate, propofol, and midazolam in 60 patients undergoing CABG $\underline{14}$. Four patients in the propofol group had ST changes prior to induction and these changes disappeared in two patients after induction. In the etomidate group also there were three patients with prior ST changes that remained unchanged, but one other patient developed ST segment deviation after induction. They explained that propofol, while reducing coronary perfusion, also decreased myocardial oxygen consumption. There were no visible ST segment changes in any of our patients and we did not do a formal analysis of ST segment changes in the four different groups.

Tarnow et al. studied in patient with severe ischemic heart disease, etomidate produced only small cardiovascular effect which is support merely to reflect physiological change from the walking to the sleeping state. They also demonstrated that addition of fentanyl results in small decrease in heart rate and a moderate fall in cardiac index ${ }^{15}$. No changes in cardiovascular dynamics occurred in association with laryngoscopy and endotracheal intubations, which is known frequently to stimulate the prime determinants of myocardial oxygen demand by reflex sympathetic discharge. The lack of cardiovascular changes during laryngoscopy and intubation is supposed to be due mainly to the relatively large doses of fentanyl. Their study also suggests the cardiovascular effects of etomidate and thiopentone were very similar, except for the small increase in heart rate which occurred with thiopentone. This finding also agrees with that of Broadley and Tailor ${ }^{16}$ who also found no major cardiovascular effects during induction $2.5 \mathrm{mg} / \mathrm{Kg}$ in patient undergoing cardiac surgery. We could not confirm the results of Sonnatag, et al ${ }^{13}$ who described marked increase in heart rate after thiopentone $4.0 \mathrm{mg} /$ $\mathrm{kg}$ which were associated with highly significant decrease in stroke volume and a 55 percent of myocardial oxygen consumption in healthy volunteer. These 
differences are supposed to be due to the fact that the majority of our patient were pretreated with â - receptor blocking agents and that all were premedicated.

In conclusion etomidate/fentanyl induction reduces less blood pressure in comparison to thiopental/fentanyl induction in patients with poor left ventricular function but changes of heart rate were in significant in between the groups. Further study is needed to establish the role of thiopentone \& etomidate with fentanyl on haemodynamic response in patient under going CABG of poor left ventricular function.

\section{References:}

1. Moffit EA, Sethna DH. The coronary circulation and myocardial oxygenation in coronary artery disease of anaesthesia. Anesth Analg 1986; 65: 395-410.

2. Kelly G, Daniel, Dan EB. Pharmacology of anaesthesitic drugs In: Kaplan's cardiac Anaesthesia. Kaplan JA, David LR, Lake CL, (eds). 5th ed. Philadelphia: Saunders Elsevier: 2006.p.185-87.

3. Haessler R, Madler C, Klasing S, Schwender D, Peter K. Propofol/fentanyl versus etomidate/fentanyl for the induction of anesthesia in patients with aortic insufficiency and coronary artery disease. J Cardiothorac Vasc Anesth. 1992; 6(2):173-80.

4. Zielmann S, Kazmaier S, Schnüll S, Weyland A. S-(+)Ketamine and circulation. Anaesthesist. 1997; 46 Suppl $1:$ S43-46.

5. Gooding JM, Weng JT, Smith RA, Berninger GT, Kirby RR. Cardiovascular and pulmonary responses following etomidate induction of anesthesia in patients with demonstrated cardiac disease. Anesth Analg. 1979; 58(1):40-41.

6. Massaut J, d'Hollander A, Barvais L, Dubois-Primo J. Haemodynamic effects of midazolam in the anaesthetized patient with coronary artery disease. Acta Anaesthesiol Scand. 1983; 27(4):299-302.

7. Reiz S, Balfors E, Friedman A, Haggmark S, Peter T. Effects of thiopentone on cardiac performance, coronary hemodynamics and myocardial oxygen consumption in chronic ischemic heart disease. Acta Anaesthesiol Scand. 1981; 25(2):103-10.

8. Stephan H, Sonntag H, Schenk HD, Kettler D, Khambatta HJ. Effects of propofol on cardiovascular dynamics, myocardial blood flow and myocardial metabolism in patients with coronary artery disease. Br J Anaesth. 1986; 58(9):969-75.

9. Bergen JM, Smith DC. A review of etomidate for rapid sequence intubation in the emergency department. J Emerg Med. 1997; 15(2):221-30.

10. Bendel S, Ruokonen E, Polonen P, Uusaro A. Propofol causes more hypotension than etomidate in patients with severe aortic stenosis: a double-blind, randomized study comparing propofol and etomidate. Acta Anaesthesiol Scand. 2007; 51(3):284-89.

11. Giese JL, Stanley TH. Etomidate: A new intravenous anesthetic induction agent. Pharmacotherapy. 1983; 5(3): 251-58.

12. Jellish WS, Riche H., Salard Francois, Ravussin P, Tempel hoff R. Etomidate and thiopental based anaesthetic induction: Comparisons between different titrated levels of electrophysiologic cortical depression and response to laryngoscopy. Journal of Clinical Anaesthesia. 1997; 9(1):36-41.

13. Sonntag H, Hellberg K, Schenk HD, Donath U, Regensburger $\mathrm{D}$, Kettler D, et al. Effects of thiopental (Trapanal) on coronary blood flow and myocardial metabolism in man. Acta Anaesthesiol Scand 1975; 19:69-78.

14. Lischke V, Probst S, Behne M, Kessler P. ST segment changes in the ECG. Anesthesia induction with propofol, etomidate or midazolam in patients with coronary heart disease. Anaesthesist 1993; 42:435-40.

15. Tarnow J, Hess W, Klein W. Etomidate, Alfathesin and Thiopentone as induction agents for coronary artery surgery. Canad. Anaesth. Soc. J. 1980; 27(4): 338-44.

16. Broadly JN \& Tailor PA. An assessment of alfathesin for the induction of anaesthesia in cardiac surgical patient: a comparison with thiopentone. Br. J. Anaesthe 1974; 46:687. 